\title{
Low Grade Cervical Glandular Intraepithelial Neoplasia
}

National Cancer Institute

\section{Source}

National Cancer Institute. Low Grade Cervical Glandular Intraepithelial Neoplasia. NCI Thesaurus. Code C7674.

Cervical glandular intraepithelial neoplasia characterized by the presence of mild dysplastic changes. 